Research Article

\title{
Sales Disclosure and Pricing Policies in the Presence of Social Learning
}

\author{
Rui Zheng $\left(\mathbb{D},{ }^{1}\right.$ Yi Yuan $(\mathbb{D})^{2}$ and Yi Li $\mathbb{D}^{2}$ \\ ${ }^{1}$ School of Safety Science and Emergency Management, Wuhan University of Technology, No. 122 Luoshi Road, \\ Wuhan 430070, China \\ ${ }^{2}$ School of Management, Xi'an Jiaotong University, No. 28 Xianning West Road, Xi'an 710049, China
}

Correspondence should be addressed to Yi Li; aaa123liyi@stu.xjtu.edu.cn

Received 14 January 2021; Revised 22 January 2021; Accepted 1 April 2021; Published 26 April 2021

Academic Editor: Fazal M. Mahomed

Copyright (C) 2021 Rui Zheng et al. This is an open access article distributed under the Creative Commons Attribution License, which permits unrestricted use, distribution, and reproduction in any medium, provided the original work is properly cited.

\begin{abstract}
This study analyzes the role of sales disclosure and social learning (SL) in firms' optimal responsive pricing policies and profits. If sales quantities are disclosed, potential customers will increase (decrease) their willingness to pay for the product based on the observation of relatively high (low) sales. In a monopoly market, a firm can control initial sales through the initial price, thus influencing consumers' SL outcomes. We find that disclosing sales quantities and enhancing SL are always beneficial for a firm in a monopoly context. With an increase in the intensity of SL, a monopoly firm has a higher incentive to decrease the initial price of a product to attract early buyers, which is beneficial for consumers. However, consumer surplus may decrease if consumers' purchase intentions are strongly driven by historical sales quantities. In a duopoly market, learning based on historical sales quantities can encourage potential customers but intensify competition between firms. Thus, in a competitive market, sales disclosure and SL are only beneficial to firms when consumers' intrinsic valuation of a product is relatively low. Otherwise, SL harms firms.
\end{abstract}

\section{Introduction}

Social learning (SL) refers to the phenomenon that people learn from others about an object of interest via social interactions [1]. With the increased popularity of online shopping and the development of social media technologies, the impact of SL on consumer product choices has never been greater. There are two main types of social interactions among consumers online, namely, word of mouth and observational learning. For example, consumers learn from other consumers' word of mouth through product reviews. They also learn from others' actual purchase decisions by merely observing how many customers have already purchased a product [2]. In the operations management area, scholars have paid great attention to consumers' learning practices through product reviews and the ways in which firms can tactically control the quality information flow and product ratings via initial prices (e.g., see [3-5]). However, few studies have explored how observational learning through previous sale volumes interacts with firms' pricing policies and profits.

Empirical evidence has shown that consumers would like to pay more for highly ranked products while less for products with low sales $[6,7]$. Therefore, disclosing historical sales volumes can either encourage or discourage potential buyers, which depends on whether or not the early market reaction is enthusiastic. Given the possible positive or negative effect of sales disclosure, we often observe in practice that some firms tend to commit to disclosing sales information, while others never release details. For example, Apple always releases iPhone and iPad sales volumes, but Amazon never announces the number of sales of Kindle products [8]. Recently, Huawei and Xiaomi, competitors in the $5 \mathrm{G}$ mobile phone market, successively released the sales quantities of their 5G mobile phones [9]. The largest online B2C retailer Tmall.com in China always releases historical sales quantities of their products, while the third-largest online B2C retailer Vip.com never releases historical sales 
quantities. The sales quantities disclosed by firms may also benefit consumers, allowing them to make better-informed purchase decisions. This paper theoretically analyzes how the disclosure of sales and SL impact firms' pricing policies, profits, and overall social welfare in both monopoly and duopoly markets.

To investigate the impact of the disclosure of sales information and SL on firms' dynamic pricing policies and profitability, we consider a two-period model. At the beginning of the first period, firms launch a new product and set a launch price for it. In period 1, consumers who like the product very much will buy it. At the beginning of the second period, firms can change selling prices based on their sales disclosure strategies and historical sales quantities accumulated in period 1. If firms disclose their historical sales volumes, consumers who remain in the second period will update their willingness to pay for the product and make purchase decisions accordingly. Particularly, potential customers may exhibit either an increase or decrease in their willingness to pay for the product based on their observation of a relatively high or low historical sales quantities. Our goal is to address the following three research questions:

(i) What is the optimal pricing policy in the presence of sales disclosure and SL in a monopoly market?

(ii) How do sales disclosure and SL impact a firm's profit and the total social welfare in a monopoly market?

(iii) What is the role of sales disclosure and SL in a duopoly competition setting?

Our main findings are as follows. In a monopoly market, a firm can control its initial sales via the initial price of a product. With the increase of SL intensity, the firm will decrease the first-period price to induce higher initial sales. In this case, sales disclosure and SL benefit both the firm and consumers. However, when the intensity of SL exceeds a certain threshold, under which potential customers' purchase intentions are strongly driven by the initial sales quantities, the firm may take advantage of SL and increase the second-period price. In this case, SL harms consumers. Overall, in a monopoly market, disclosing sales quantities and encouraging consumer learning based on these quantities are always beneficial for the firm and the total social welfare.

In a competitive market where two firms sell the same product (or two horizontally differentiated products with some common new technologies), the role of sales disclosure and SL may be different. More specifically, in a competitive market, disclosing sales volumes and inducing consumers to learn are likely to encourage potential customers and increase their purchase intention. This increase in consumers' purchase intention has two opposite effects. On the one hand, more consumers may adopt the product. On the other hand, increase in consumers' enthusiasm for the product may intensify competition between the firms. Therefore, in a competitive market, disclosing sales information can increase a product's popularity and benefit firms only when consumers' intrinsic valuation of the product is relatively low. When consumers' initial valuation of the product is already high, SL can further increase potential customers' desire for that product. This increased desire intensifies the competition and harms firms and the overall social welfare.

Our analysis yields two main managerial insights. First, in a monopoly market, when a firm can leverage an enthusiastic market reaction to attract potential customers, the firm should lower its profit margin and achieve great profit through a high market penetration rate. Namely, the firm can adopt a mass pricing strategy in a monopoly market in the presence of sales disclosure and SL. Second, in a competitive market where two competing firms sell the same product or two horizontally differentiated products with some standard new technologies, it is optimal for the firms to release their sales quantities at an early stage. Announcing sales quantities early can increase a new product's or technology's popularity, benefiting the two competing firms. At a later stage, when most consumers have already accepted the new product or technology and are willing to pay for it, there is no need for firms to release sales quantities. In this case, released sales quantities and SL may result in more intense and harmful competition between firms.

The remainder of this paper is organized as follows. Section 2 reviews the related literature. Section 3 analyzes a monopoly firm's optimal pricing policy and profit in the presence of sales disclosure and SL activities. Following this analysis, Section 4 studies the role of sales disclosure and SL in a competitive duopoly market. Finally, Section 5 concludes the paper.

\section{Related Literature}

Our study contributes to the stream of literature that explores consumers' SL behavior and firms' optimal operational strategies in the presence of SL. As early as 1992, Banerjee [10] and Bikhchandani et al. [11] have demonstrated that consumer learning based on the observation of other consumers' purchase decisions may lead to the phenomenon of herding in human choices. Following the learning model in Banerjee [10], Liu and Schiraldi [12] studied a monopoly firm's optimal product launch strategy in the presence of SL. They found that the optimal launch strategy depends on consumers' prior belief of a product's value and the adoption cost faced by potential customers. In recent years, the explosion of social media has significantly increased the scope of SL among consumers. Zhang et al. [13] compared observational learning from friends versus strangers. Consumers exhibited greater preference heterogeneity in the stranger network than in the friend network. The authors found that as a network grows, learning from strangers becomes more effective for consumers to obtain true product quality. Our study expands research on consumer learning behavior based on the observation of other consumers' purchase decisions. We adopt a simple but relevant model to characterize consumer learning behavior: consumers may increase or decrease their willingness to pay for a product based on their observation of relatively high or low historical sales quantities. 
Scholars have also begun to explore how firms can tactically optimize their prices by considering the interaction between product prices and consumers' SL behaviors. For instance, Yu et al. [3] and Papanastasiou and Savva [4] have examined the monopoly dynamic pricing problem of newly launched products in the presence of SL and strategic consumer behavior. Crapis et al. [5] have studied a monopoly firm's pricing problem under SL where consumers arrive according to a Poisson process. These studies demonstrate that the incorporation of consumers' SL behavior into pricing policies improves the firms' profits. In addition, consumers' strategic delay of their consumption in order to wait for early buyers' product reviews can harm firms. Feldman et al. [14] presented a new aspect for firms to consider in adapting to consumers' SL behavior. They suggested that firms consider the impact of SL as early as the product design stage. The studies mentioned above all conceptualize consumers' learning based on early buyers' product reviews. Jing [1] conceptualized consumers' SL behavior by assuming that the probability of a potential customer discovering a product's value was a linear function of the product's initial adoption rate. Peng et al. [15] investigated a seller's optimal price guarantee policy for advance selling when potential customers practice learning based on preorder quantities. Following this stream of literature, our study systematically analyzes the role of historical sales quantities and SL in firms' pricing policies in a monopoly market.

There are relatively few studies on competing firms' pricing policies in the presence of SL. Hu et al. [16] examined the pricing and inventory strategies of a firm that sells two horizontally differentiated, substitutable products under the impact of social influence. The authors conceptualize social influence based on the assumption that a later consumer's willingness to pay for a product increases with the product's historical sales quantities. Following the study of Hu et al. [16], Sun et al. [7] examined a two-period pricing problem of competing firms in the presence of social influence. The authors found that in a competitive setting, firms' profits always decrease with the degree of social influence. Jiang and Wang [17] provided a theoretical framework for understanding how product ratings influence firms' optimal pricing policies and profits. The authors have found that an increase in a product's rating in a monopoly setting always increases a firm's profit. In contrast, in a duopoly setting, an increase in a product's rating may intensify competition and decrease a firm's profit. Our study contributes to this body of literature through an investigation of the optimal pricing strategy of competing firms in the presence of SL. Unlike existing studies, this study models a different aspect of consumers' SL behavior in a competitive market. In this model, a consumer's observation of a firm's product's high sales may also prompt an increase in the popularity of a competitor's product that uses the same technology [18].

Our paper also relates to studies that explore firms' optimal sales disclosure strategies. Scholars have tried to investigate the impact of sales disclosure on firms' profit through the lens of both theoretical and empirical perspectives. For example, a pioneering study by Parakhonyak and Vikander [19] proves that to best exploit network effects, firms should release preorder and sales information to consumers for network goods. Hu et al. [8] also studied the sales volume disclosure and pricing problems associated with network goods. The authors systematically analyzed the positive and negative effects of sales disclosure. In another study, $\mathrm{Hu}$ et al. [20] demonstrated that in the group buying business model, it is always more beneficial for a firm to disclose the number of sign-ups already accumulated to potential customers rather than not do so. Chen et al. [2] and Xie et al. [21] have empirically verified that the disclosure of sales history can significantly increase subsequent transactions. Contributing to this stream of literature, this study theoretically proves that when historical sales quantities can influence potential customers' willingness to pay for a product, disclosing sales quantities is always beneficial for monopoly firms but may harm firms in competitive markets.

\section{Monopoly Market}

We first analyze the role of sales disclosure and SL in a monopoly firm's pricing policy and profit. In this section, we consider a monopoly firm that launches a new product. The product is sold in a two-period time window. The firm responsively decides the selling price at the beginning of each period to maximize its total profit in the two periods. There is a mass of $N$ consumers in the market, where $N$ is common knowledge. Each consumer needs at most one unit of the product in the whole selling time window. Consumers have heterogeneous prior valuations of the product, denoted by $\theta$, which follows a uniform distribution on $[0,1]$.

The game in this monopoly setting proceeds as follows. At the beginning of period 1 , the firm sets price $p_{1}$. After observing $p_{1}$, consumers decide whether or not to purchase the product. In this study, we assume consumers are myopic and they will not strategically delay their purchase. Consumers with high valuations of the product (i.e., no less than $p_{1}$ ) will buy the product in period 1. Let $\alpha$ denote the proportion of consumers who purchase the product by the end of period 1. We also call $\alpha$ the product's initial adoption rate. At the beginning of the second period, the firm discloses the product's sales quantities accumulated in period 1 and sets price $p_{2}$ for the second period. The remaining $(1-\alpha) N$ consumers who did not purchase the product in the first period observe the initial sales and derive the initial adoption rate $\alpha$. Based on this information, they update their valuations of the product. Then, the second-period consumers make purchase decisions based on their updated valuations and the secondperiod price.

Consumer's SL Rule. We adopt a linear learning rule to characterize consumer learning behavior based on historical sales quantities, in particular, we assume that consumers' posterior valuation of the product after observing sales quantities in period 1 satisfies the following equation:

$$
\widetilde{\theta}=\beta \alpha+(1-\beta) \theta,
$$


where $\widetilde{\theta}$ represents consumers' updated valuation of the product and $\alpha$ represents the product adoption rate by the end of period 1. Through the observation of historical sales quantities, consumers obtain the product adoption rate $\alpha . \beta(0 \leq \beta \leq 1)$ represents consumers' SL intensity, which reflects the magnitude of social influence on a consumer's product valuation. A larger $\beta$ indicates a stronger influence of SL. When $\beta=0$, the consumers' updated valuation is the same as their prior valuation; when $\beta=1$, the updated valuation is entirely based on SL. A linear learning rule is often used in modeling consumers' observational learning behavior based on historical sales quantities $[1,22,23]$. This novel learning rule ensures the tractability of the study's analysis while still capturing the essence of the impact of historical sales quantities on consumers' willingness to pay. For example, when sales in period 1 are high (i.e., a larger $\alpha$ ), SL can increase most consumers' valuations in period 2. However, if the initial sales are low, later consumers' valuations are likely to decrease.

3.1. Optimal Pricing Strategy and Profit. The equilibrium pricing strategy can be derived through backward induction. Given the product adoption rate $\alpha$ in period 1, a consumer who remains in the market will buy the product only if $U_{2}=\beta \alpha+(1-\beta) \theta-p_{2} \geq 0$, which is equivalent to $\theta \geq\left[p_{2}-\beta \alpha /(1-\beta)\right]^{+}$. Therefore, consumers' demand in period 2 satisfies $D_{2}=\left\{\begin{array}{ll}{\left[1-\alpha-\left(p_{2}-\beta \alpha /(1-\beta)\right)\right] N} & \text { if } p_{2}>\beta \alpha \\ (1-\alpha) N & \text { otherwise }\end{array}\right.$ In period 2, the firm decides the optimal price $p_{2}$ to maximize its profit, $\Pi_{2}\left(p_{2} \mid \alpha, p_{1}\right)$, where $\Pi_{2}\left(p_{2} \mid \alpha, p_{1}\right)=p_{2} D_{2}$. We can derive the firm's optimal pricing policy in period 2 as $p_{2}^{*}=\left\{\begin{array}{ll}(1-\beta+(2 \beta-1) \alpha / 2) & \text { if } 0 \leq \alpha \leq 1-\beta \\ \beta \alpha & \text { if } 1-\beta<\alpha \leq 1\end{array}\right.$ and the optimal profit in period 2 satisfies $\Pi_{2}^{*}=\left\{\begin{array}{ll}\left(N[1-\beta+(2 \beta-1) \alpha]^{2} / 4(1-\beta)\right) & \text { if } 0 \leq \alpha \leq 1-\beta \\ N \alpha(1-\alpha) \beta & \text { if } 1-\beta<\alpha \leq 1\end{array}\right.$.

In period 1 , a consumer will buy the product if his or her consumption utility satisfies $U_{1}=\theta-p_{1} \geq 0$. It is straightforward that $\alpha=1-p_{1}$. In period 1 , the firm decides $p_{1}$ to maximize its total profit in the two periods, which satisfies $\Pi=p_{1} \alpha N+\Pi_{2}^{*}$. The optimal pricing strategy and profit are summarized in Proposition 1.

\section{Proposition 1}

(i) If $0 \leq \beta \leq(1 / 2)$, then $p_{1}^{*}=\left(2-\beta-2 \beta^{2} / 3-4 \beta^{2}\right)$, $p_{2}^{*}=\left(1-\beta / 3-4 \beta^{2}\right)$, and $\Pi^{*}=\left(N\left(1-\beta^{2}\right) / 3-\right.$ $\left.4 \beta^{2}\right)$; if $(1 / 2)<\beta \leq 1$, then $p_{1}^{*}=(1 / 2), p_{2}^{*}=(\beta / 2)$, and $\Pi^{*}=(N(1+\beta) / 4)$.

(ii) $p_{1}^{*} \geq p_{2}^{*}$.

(iii) $p_{1}^{*}$ first decreases with $\beta$ and then remains constant with $\beta$.

(iv) $p_{2}^{*}$ first decreases with $\beta$ and then increases with $\beta$.

(v) $\Pi^{*}$ is convex and increasing of $\beta$.

Benchmark: No Sales Disclosure. In the case that the firm does not disclose sales quantities at the beginning of period
2, consumers who remain in period 2 will not update their valuations. In this case, it is easy to derive the firm's optimal pricing policy in the two periods which satisfies $p_{\text {lben }}^{*}=$ $(2 / 3)$ and $p_{2 \text { ben }}^{*}=(1 / 3)$. Correspondingly, the optimal profit satisfies $\Pi_{\text {ben }}^{*}=(N / 3)$. Moreover, we can derive that when there is no sales disclosure, the total consumer surplus equals $(N / 9)$ and the total social welfare is $(4 N / 9)$. It is easy to check that the optimal pricing policy in the no sales disclosure case is the same as the pricing policy under $\beta=0$ in the sales disclosure case.

Figure 1 illustrates the findings in Proposition 1. In this numerical example, we use $N=100$. The results state that as SL intensity increases, the firm decreases its first-period price to attract early buyers. Moreover, since SL may decrease second-period consumers' willingness to pay, the firm also decreases its second-period price when the intensity of SL is lower than a certain threshold. This implies that when a firm can utilize historical sales quantities to influence customers' purchase intentions, the firm should lower its profit margin and achieve great profit through a high market coverage rate. When SL intensity reaches a certain level, it is optimal for the seller to cover the whole market. In this case, the optimal pricing policy makes half of the consumers purchase the product in period 1 and SL increases the remaining consumers' valuations of the product. Due to the increase of their product valuations, the optimal second-period price increases with the learning intensity. In general, the firm adopts a decreasing-pricing strategy in the two periods (i.e., $\left.p_{2}^{*} \leq p_{1}^{*}\right)$, which is consistent with the findings of existing literature (e.g., $[1,4])$. Interestingly, although SL may decrease consumers' product valuations, stronger learning intensity always leads to greater profits. From Figure 1(b), we can see that in this monopoly setting, disclosing sale information and enhancing SL are always beneficial for the firm.

3.2. The Role of SL in Consumer Surplus and Total Social Welfare. Let $\mathrm{CS}_{k}$ denote consumers' surplus in period $i$ $i \in\{1,2\}$. Define CS: $=\mathrm{CS}_{1}+\mathrm{CS}_{2}$ which represents the total consumer surplus and $W:=\Pi^{*}+\mathrm{CS}$ which represents the total social welfare. The details of consumer surplus and total social welfare are summarized in Table 1 . Proposition 2 summarizes how SL impacts the consumer surplus and total social welfare.

\section{Proposition 2}

(i) When $0 \leq \beta \leq(1 / 2)$, the consumer surplus increases with $\beta$; otherwise, the consumer surplus decreases with $\beta$.

(ii) The total social welfare increases with $\beta$.

Figure 2 illustrates the findings in Proposition 2. In this numerical example, we still use $N=100$. When the intensity of SL is lower than a certain threshold, with an increase in SL intensity, the firm will decrease product prices, which is beneficial for consumers. Therefore, when the learning intensity is lower than a certain threshold, consumer surplus 


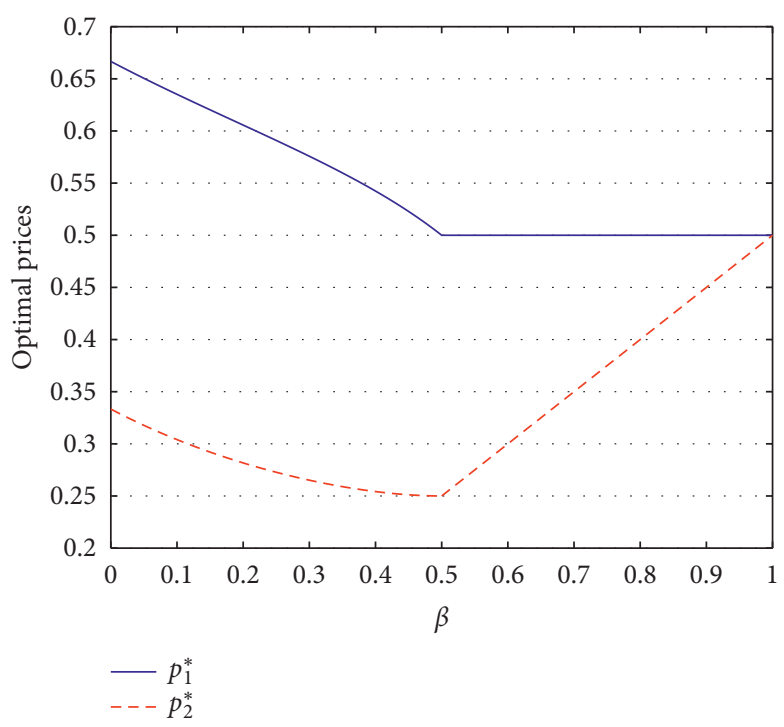

(a)

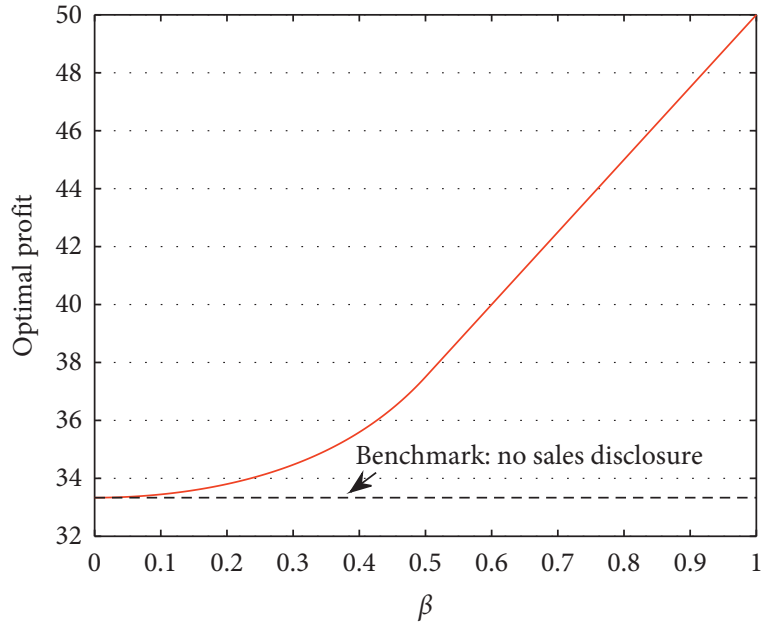

(b)

FIgURE 1: The optimal pricing policy and profit in a monopoly market. (a) Optimal prices w.r.t. $\beta$. (b) Optimal profit w.r.t. $\beta$.

increases with SL intensity. However, when the intensity of SL exceeds a certain threshold, consumers' purchase intention in the second period is strongly influenced by a product's initial sales. In this case, firms can utilize high initial sales to influence potential customers' purchase intentions and charge a higher price with an increase in learning intensity, which would decrease consumer surplus. Second, we find that disclosing historical sales quantities in a monopoly market is always beneficial for total social welfare. The intuition is that the pressure of sales disclosure leads a firm to charge a lower product price, which enables more consumers to consume the product.

\section{Duopoly Market}

In this section, we analyze the role of sales disclosure and SL in a competitive market. We consider the case of two competing firms selling the same newly launched product (or two horizontally differentiated products) in a market. For example, Huawei and Xiaomi are competitors in the 5G mobile phone market. They successively released the sales quantities of their $5 \mathrm{G}$ mobile phones. The duopoly competition model follows the classic Hotelling model. Two firms, $A$ and $B$, sell the same product (or horizontally differentiated products) in two periods. There are a total of $N$ consumers in the market. Consumers are uniformly distributed along a horizontal $[0,1]$ line with unit density. Each consumer demands at most one unit of the product in the two periods. Each firm offers a product at one end of the market. For example, firm $A$ 's product is at point 0 , and firm $B$ 's product is at point 1 . Consumer $x$ 's utility from consuming products from the two firms in period $i$ (for $i \in\{1,2\}$ ) satisfies

$$
\begin{aligned}
& u_{i A}=v_{i}-t x-p_{i A}, \\
& u_{i B}=v_{i}-t(1-x)-p_{i B},
\end{aligned}
$$

where $v_{i}$ denotes consumers' intrinsic valuation of the product in period $i$. Since consumers in period 2 may observe the firms' initial sales and update their intrinsic valuation for the product, $v_{2}$ may be different with $v_{1} . t \geq 0$, which represents consumers' unit traveling cost. $p_{i k}$ (for $k \in\{A, B\}$ ) represents firm $k$ 's price in period $i$, and $x$ is the consumer's location on the horizontal line, which indicates the consumer's product or brand preference.

The game proceeds as follows. In period 1, the two firms publicly and simultaneously announce prices $p_{1 A}$ and $p_{1 B}$ of their products. Consumers are myopic, and after observing the two firms' prices in period 1, consumers with a strong preference for firm A's product will buy from firm A. Similarly, consumers who have a strong preference for firm B's product will buy from firm B. Some consumers in the middle range may choose not to buy the product in period 1. If any consumer remains in the market in period 2 , the two firms would again simultaneously quote prices $p_{2 A}$ and $p_{2 B}$. In period 2 , consumers update their valuations of the product based on the initial adoption rate of the product and make purchase decisions based on their updated product valuation and the second-period product prices.

\subsection{Consumers' Purchase Decision and SL Behavior}

4.1.1. Purchase Decision in Period 1. In period 1, consumers with a strong preference for firm $A$ 's product will buy from firm $A$ in period 1 (namely, when $u_{1 A} \geq 0$ and $u_{1 A} \geq u_{1 B}$ ). On the other hand, consumers with a strong preference for firm B's product will buy from firm B in period 1 (namely, when $u_{1 B} \geq 0$ and $u_{1 B} \geq u_{1 A}$ ). Consumers who do not have a strong preference for the product will not buy. Let $\alpha_{k}$ denote the product adoption rate of firm $k$ 's product in period 1 . We can prove the following threshold structure of consumers' purchase decision in period 1 . 


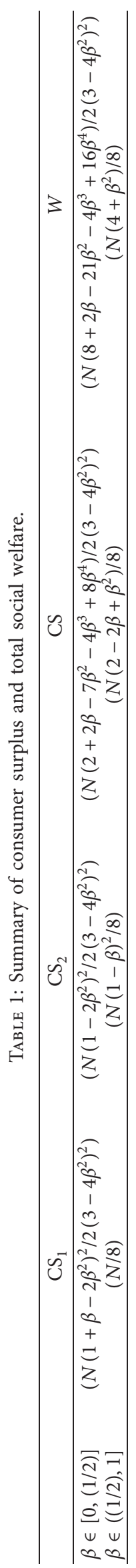




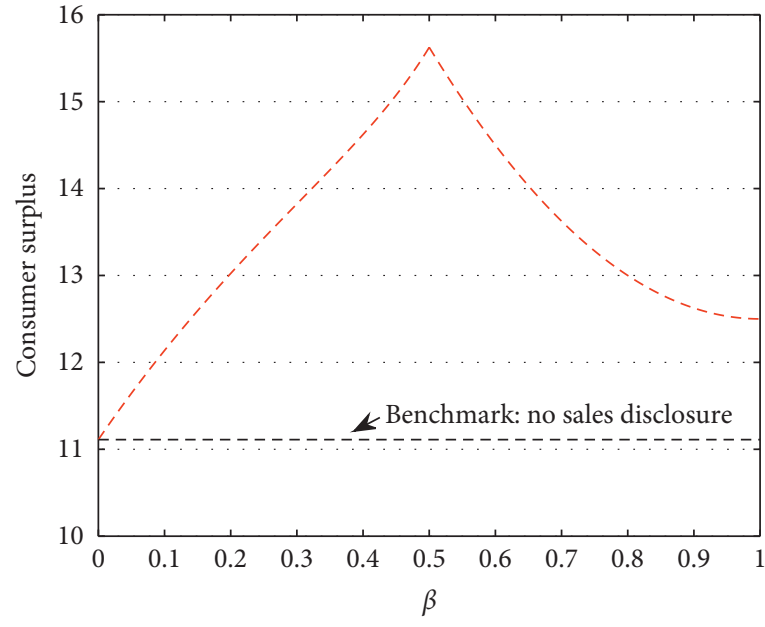

(a)

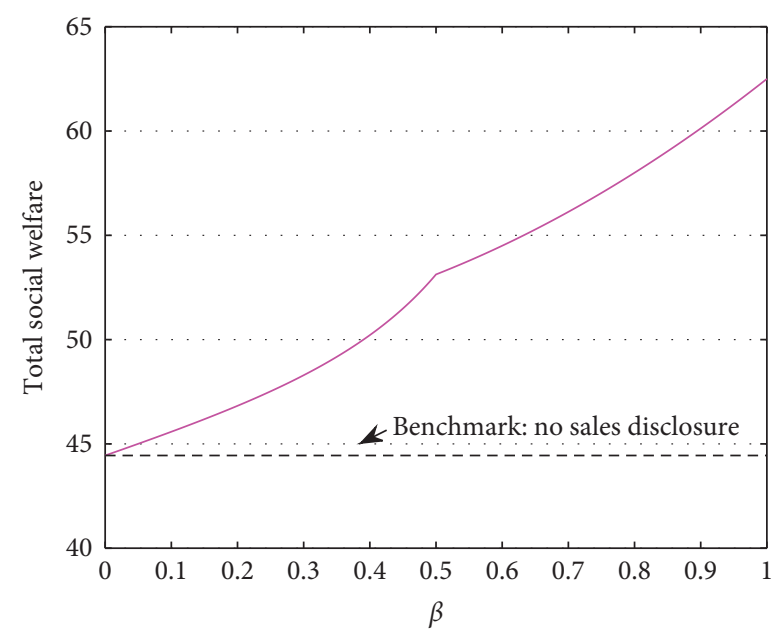

(b)

Figure 2: The total consumer surplus and social welfare in a monopoly market. (a) Consumer surplus w.r.t. $\beta$. (b) Total social welfare w.r.t. $\beta$.

$$
\tau\left(x, p_{1 A}, p_{1 B}\right)= \begin{cases}A & \text { if } x \leq \alpha_{A}, \\ \varnothing & \text { if } \alpha_{A}<x<1-\alpha_{B}, \\ B & \text { if } x \geq 1-\alpha_{B},\end{cases}
$$

where $\tau\left(x, p_{1 A}, p_{1 B}\right)$ represents consumer $x$ 's product choice in period 1 given the prices of the two firms' product in period 1 . When faced with $\left(p_{1 A}, p_{1 B}\right)$, consumers whose distance to firm $A$ is less or equal to $\alpha_{A}$ will purchase from firm $A$, while those whose distance to firm $B$ is less or equal to $\alpha_{B}$ will purchase from firm $B$, and those located in a middle range will not purchase.

4.1.2. Purchase Decision in Period 2. At the beginning of period 2, both firms announce their sales quantities in period 1 , based on which the second-period consumers can derive the product adoption rates $\alpha_{A}$ and $\alpha_{B}$ in period 1. Similar to the learning rule in the monopoly model, in the case of competition, second-period consumers update their intrinsic valuation of the product based on the following learning rule:

$$
v_{2}=\beta\left(\alpha_{A}+\alpha_{B}\right)+(1-\beta) v_{1},
$$

where $v_{2}$ represents a consumer's updated intrinsic valuation of the product, which is a weighted average of his or her initial intrinsic valuation and the initial adoption rate. In this study, we normalize $v_{1}$ to $[0,1]$. $\left(\alpha_{A}+\alpha_{B}\right)$ represents the total adoption rate of the product by the end of period 1 . $\beta$ represents the SL intensity with $0 \leq \beta \leq 1$. A larger value of $\beta$ indicates a stronger influence of SL on consumers' posterior product valuation. This learning rule demonstrates that for two competing firms selling the same product or two horizontally differentiated products with the same technology, the good selling of one firm's product may prompt an increase in the popularity of the other firm's product. For example, the popularity of Huawei's $5 \mathrm{G}$ mobile phone may improve consumers' intention to adopt $5 \mathrm{G}$ technology and increase the sales of the Xiaomi 5G mobile phone. This is also known as the advertising effect for two competing products in the marketing literature [18].

Consumers who remain in period 2 make purchase decisions based on their updated valuations of the products. A consumer will purchase from firm $A$ (firm $B$ ) only if $u_{2 A} \geq 0\left(u_{2 B} \geq 0\right)$ and $u_{2 A} \geq u_{2 B}\left(u_{2 B} \geq u_{2 A}\right)$.

4.2. Firms' Optimal Pricing Strategy. We analyze the optimal responsive pricing strategy of the firms through backward induction. First, the equilibrium outcome of the optimal pricing strategy in period 2 is consistent with the well-known horizontal differentiation model. The results are summarized in Lemma 1. Without loss of generality, we set $t=$ $(1 / 2)$ in this section to simplify the analysis. Since $v_{1} \in[0,1]$, $\left(v_{1} / t\right) \in[0,2]$ includes different market coverage scenarios in the Hotelling model $[24,25]$. We consider the symmetric equilibrium of the two firms in this paper, which means that at equilibrium, the two firms adopt the same pricing strategy and achieve the same profit. The symmetric equilibrium of the Hotelling competition model is well documented in the literature [26].

Lemma 1. Given the product adoption rate $\alpha_{k}$ (for $k \in\{A, B\})$ in period 1, firm $k$ 's optimal pricing policy and profit in period 2 satisfy

(i) If $0 \leq v_{2}<\left(\left(1-\alpha_{k}\right) / 2\right)$, then $p_{2 k}^{*}=\left(\left[v_{2}-\right.\right.$ $\left.\left.(1 / 2) \alpha_{k}\right]^{+} / 2\right)$ and $\pi_{2 k}^{*}=\left(N\left(\left[v_{2}-(1 / 2) \alpha_{k}\right]^{+}\right)^{2} / 4\right)$.

(ii) If $\left(\left(1-\alpha_{k}\right) / 2\right) \leq v_{2}<(3 / 4)-\alpha_{k}$, then $p_{2 k}^{*}=\left(v_{2}-\right.$ $(1 / 4))$ and $\pi_{2 k}^{*}=N\left(v_{2}-(1 / 4)\right)\left((1 / 2)-\alpha_{k}\right)$.

(iii) If $v_{2} \geq(3 / 4)-\alpha_{k}$, then $p_{2 k}^{*}=(1 / 2)-\alpha_{k}$ and $\pi_{2 k}^{*}=$ $N\left((1 / 2)-\alpha_{k}\right)^{2}$.

Consistent with the equilibrium outcomes in classic horizontal differentiation models, we can see that when consumers' updated intrinsic valuation of the product is low 
(i.e., when $\left.0 \leq v_{2}<\left(\left(1-\alpha_{k}\right) / 2\right)\right)$, the market is not fully covered at equilibrium, and the firms act as local monopolies. As $v_{2}$ increases, the market covered increases until the two firms start to compete. More specifically, when $\left(\left(1-\alpha_{k}\right) / 2\right) \leq v_{2}<(3 / 4)-\alpha_{k}$, each firm set its price at $v_{2}-$ $(1 / 4)$ and covers half of the remaining market. Finally, when $v_{2} \geq(3 / 4)-\alpha_{k}$, the two firms compete intensely with each other, and half of the consumers purchase from firm $A$, while the other half of the consumers purchase from firm $B$.

In period 1, based on the definition of $\alpha_{A}$ and $\alpha_{B}$, the first-period prices satisfy $v_{1}-(1 / 2) \alpha_{A}-p_{1 A}=0$ and $v_{1}-(1 / 2) \alpha_{B}-p_{1 B}=0$, namely, the first-period prices satisfy $p_{1 A}=\left(v_{1}-(1 / 2) \alpha_{A}\right)$ and $p_{1 B}=\left(v_{1}-(1 / 2) \alpha_{B}\right)$. Therefore, firm $k$ 's profit optimization problem can be written as follows:

$$
\begin{aligned}
& \max _{\alpha_{k}} \quad \Pi_{k}=N\left(v_{1}-\frac{1}{2} \alpha_{k}\right) \alpha_{k}+\pi_{2 k}^{*}\left(\alpha_{k}\right) \\
& \text { s.t. } \quad 0 \leq \alpha_{k} \leq \frac{1}{2} .
\end{aligned}
$$

The problem of firm $A$ and firm $B$ is symmetric, and at equilibrium, $p_{i A}=p_{i B}$ and $\alpha_{A}=\alpha_{B}$. The firm's optimal pricing policy and profit are summarized in Proposition 3.

\section{Proposition 3}

Case 1. When $0 \leq \beta<(1 / 4)$ :

(i) If $0 \leq v_{1}<(1-4 \beta) /(4(1-\beta))$, then $\alpha_{k}^{*}=2(3+$ $\left.5 \beta-4 \beta^{2}\right) v_{1} /\left(7+8 \beta-16 \beta^{2}\right)$. $p_{1 k}^{*}=\left(4+3 \beta-12 \beta^{2}\right)$ $v_{1} /\left(7+8 \beta-16 \beta^{2}\right), \quad p_{2 k}^{*}=2(1+2 \beta) v_{1} /(7+8 \beta-$ $\left.16 \beta^{2}\right)$, and $\Pi_{k}^{*}=2 N\left(2+3 \beta-3 \beta^{2}\right) v_{1}^{2} /(7+8 \beta-$ $\left.16 \beta^{2}\right)$.

(ii) If $(1-4 \beta) /(4(1-\beta)) \leq v_{1}<1 /(2(1-\beta))$, then $\alpha_{k}^{*}=$ $\alpha_{k 1}^{*}, p_{1 k}^{*}=v_{1}-(1 / 2) \alpha_{k 1}^{*}$.

(iii) If $1 /(2(1-\beta)) \leq v_{1}<3(1+4 \beta) /(4(1+5 \beta))$, then $\alpha_{k}^{*}=\left(3-4(1-\beta) v_{1}\right) /(4+8 \beta), \quad p_{1 k}^{*}=3\left[4(1+\beta) v_{1}-\right.$ $1] /(8+16 \beta), \quad p_{2 k}^{*}=\left(4(1-\beta) v_{1}+4 \beta-1\right) /(4+8 \beta)$, and $\Pi_{k}^{*}=N\left[\left(v_{1}-(1 / 2) \alpha_{k}^{*}\right) \alpha_{k}^{*}+\left((1 / 2)-\alpha_{k}^{*}\right)((1 / 2)-\right.$ $\left.\left.\alpha_{k}^{*}\right)\right]$.

(iv) If $(3(1+4 \beta)) /(4(1+5 \beta)) \leq v_{1} \leq 1$, then $\alpha_{k}^{*}=(1 / 2)$, $p_{1 k}^{*}=v_{1}-(1 / 4)$ and $\Pi_{k}^{*}=\left(N\left(4 v_{1}-1\right) / 8\right)$.

Case 2. When $1 / 4 \leq \beta<1$ :

(i) If $0 \leq v_{1}<1 /(2(1-\beta))$, then $\alpha_{k}^{*}=\alpha_{k 2}^{*}, \quad p_{1 k}^{*}=$ $v_{1}-(1 / 2) \alpha_{k 2}^{*}$.

(ii) If $(1 / 2(1-\beta)) \leq v_{1} \leq 1$, then $\alpha_{k}^{*}=(1 / 2), \quad p_{1 k}^{*}=$ $v_{1}-(1 / 4)$, and $\Pi_{k}^{*}=\left(N\left(4 v_{1}-1\right) / 8\right)$.

In general, there are three market coverage scenarios at equilibrium based on consumers' intrinsic valuation of the product (i.e., $v_{1}$ ). The first scenario is that consumers' intrinsic valuation of the product is relatively low, at which point the market is not covered by the end of period 2. The second scenario describes consumers' intrinsic valuation of the product which is at a middle level where the market is not covered by the end of period 1 but covered by the end of period 2. Finally, if consumers' intrinsic valuation of the product is very high, the market is covered in period 1 . Proposition 3 presents more details of the equilibrium pricing strategy and profit. For example, when the intensity of SL is relatively low and consumers' intrinsic valuation of the product is lower than a threshold (i.e., when $0 \leq \beta<(1 / 4)$ and $\left.0 \leq v_{1}<((1-4 \beta) / 4(1-\beta))\right)$, the market is not covered by the end of period 2. In contrast, when $(3(1+4 \beta) / 4(1+5 \beta)) \leq v_{1} \leq 1$, the market is covered in period 1 , and the optimal pricing policy makes $\alpha_{A}^{*}=\alpha_{B}^{*}=(1 / 2)$. The details of $\alpha_{k 1}^{*}$ and $\alpha_{k 2}^{*}$ defined in Proposition 3 are summarized in the Appendix.

Proposition 4. In the case that $0 \leq \beta<(1 / 4)$, we have

(i) When $0 \leq v_{1}<(1-4 \beta / 4(1-\beta))$, $\Pi_{k}^{*}$ increases with $\beta$.

(ii) When $(1 / 2(1-\beta)) \leq v_{1}<(1 / 2)$, $\Pi_{k}^{*}$ increases with $\beta$.

(iii) When $(1 / 2) \leq v_{1} \leq(3(1+4 \beta) / 4(1+5 \beta))$, $\Pi_{k}^{*}$ is nonincreasing in $\beta$.

(iv) When $(3(1+4 \beta) / 4(1+5 \beta)) \leq v_{1} \leq 1, \quad \Pi_{k}^{*} \quad$ keeps constant with $\beta$.

We explore how sales disclosure and SL impact the firms' profit. We can obtain analytical results on the properties of the optimal profit when SL intensity is relatively small (i.e., when $0 \leq \beta \leq(1 / 4))$. The details are summarized in Proposition 4 . There exists a certain threshold of consumer's intrinsic valuation of the product, and when consumer's intrinsic valuation is lower than the threshold, the firms' optimal profits increase with the SL intensity. However, if the consumer's initial intrinsic valuation is high, the firms' optimal profits are non-increasing with the SL intensity. When $(1 / 4)<\beta \leq 1$, it is complex to prove how SL impacts the profit analytically. We numerically test the properties, as illustrated in Figure 3 (we still use $N=100$ ). We can see that for $\beta \in[0,1]$, when consumers' intrinsic valuation of the product is relatively low (e.g., when $v_{1}=0.2$ (Figure $3(\mathrm{a})$ )), the firm's profit increases with the intensity of SL. However, when $v_{1}=0.6$ (Figure $3(\mathrm{~b})$ ), the optimal profit decreases with the learning intensity.

Generally, how sales disclosure and SL impact firms' profit depends on consumers' initial intrinsic valuation of the product. The underlying reason is as follows. In a competitive market, sales quantities disclosed by firms are likely to increase consumers' intrinsic valuation of the product. This increase in consumers' valuation has two opposite effects. On the one hand, an increased valuation means more consumers will adopt the product or a higher price can be charged. On the other hand, an increase in consumers' willingness to pay for the product leads to more intense and harmful competition between the two firms. If consumers' initial valuation is relatively low, then an increased valuation's positive effect dominates the negative effect. In this case, utilizing historical sales quantities to prompt potential customers' acceptance of the new product or technology benefits both firms. In contrast, when consumers' initial valuation of the product is already high, then the negative effect of an increase in consumer valuation exceeds the positive 


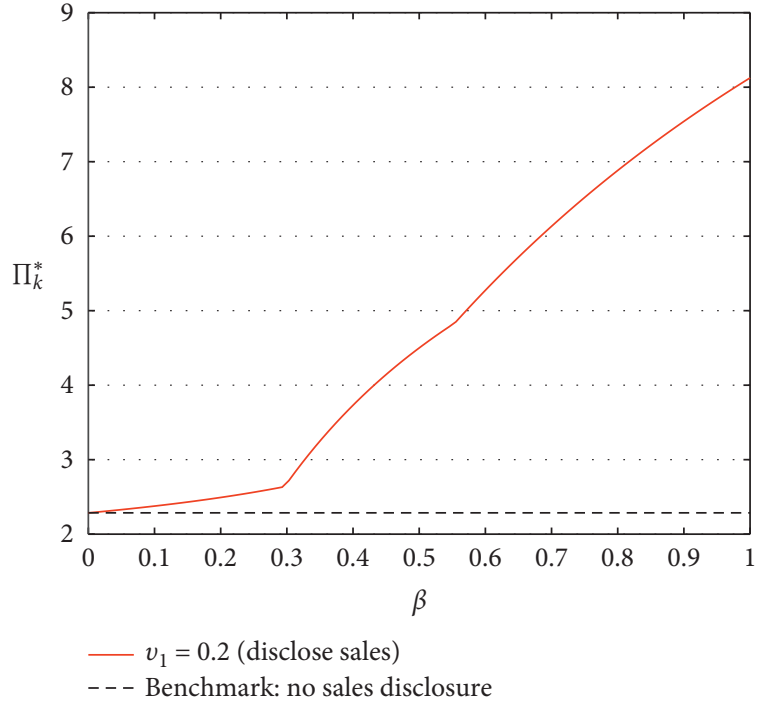

(a)

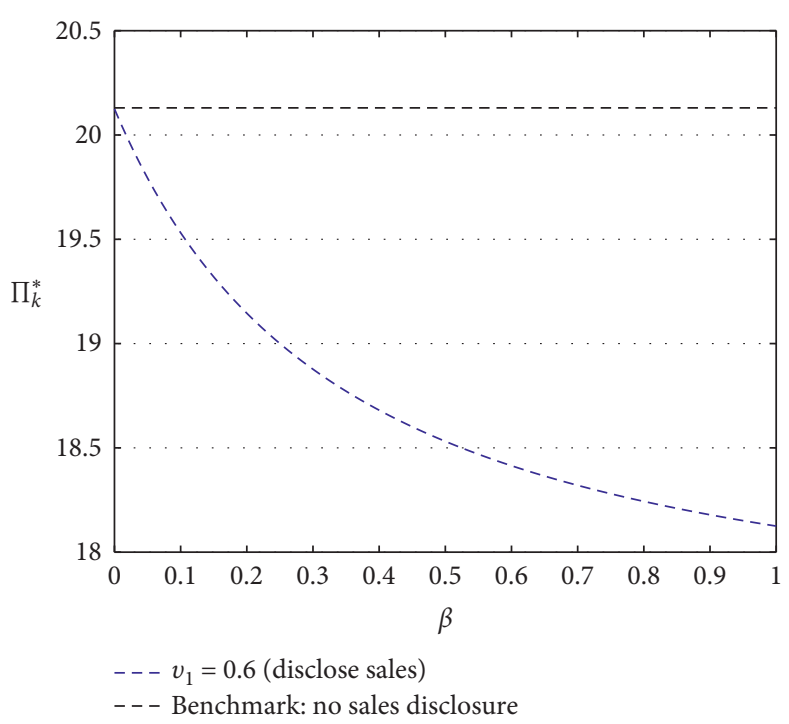

(b)

Figure 3: The firm's optimal profit w.r.t. $\beta$ in a duopoly market.

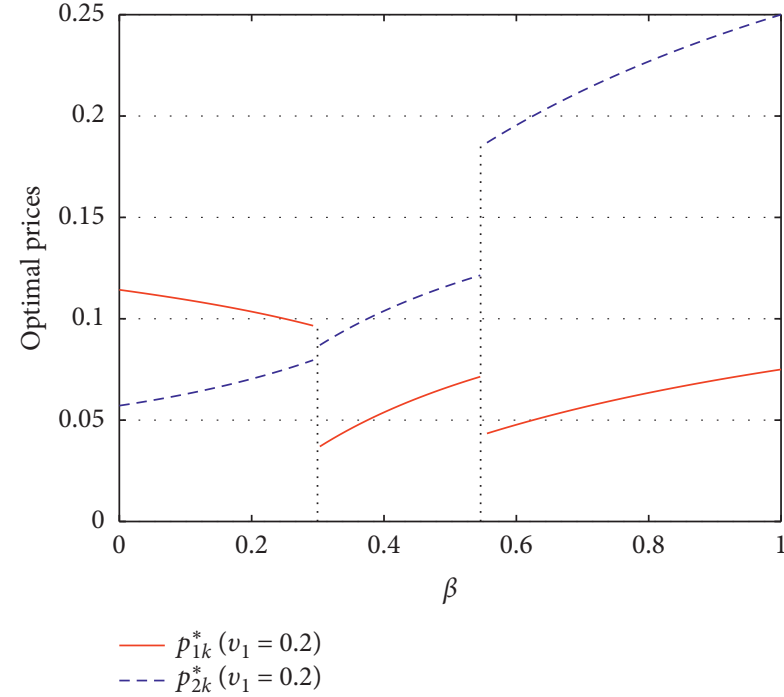

(a)

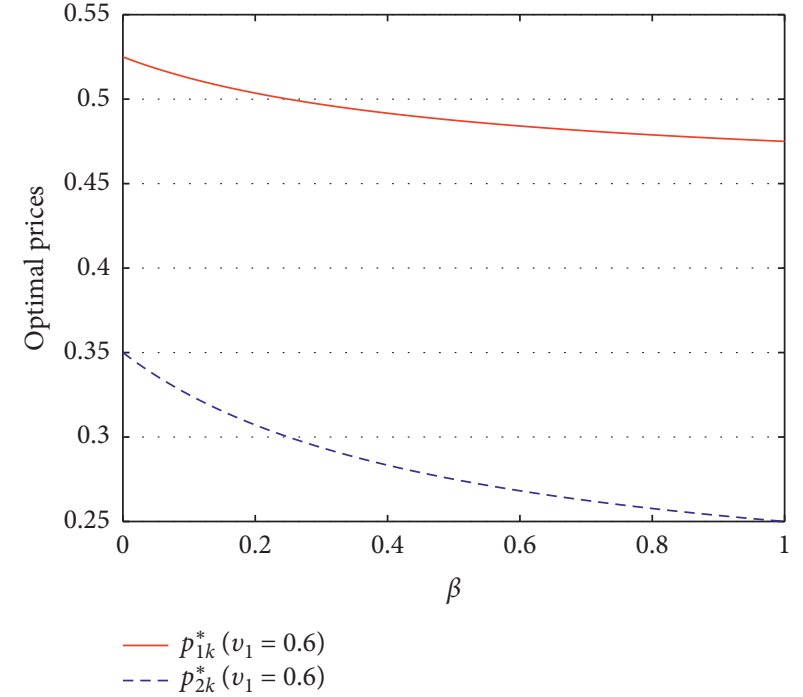

(b)

Figure 4: The optimal prices w.r.t. $\beta$ in a duopoly market.

effect. In this case, disclosing sales quantities and inducing consumers to learn harm both firms.

Next, we numerically analyze how sales disclosure and SL interact with the firms' optimal pricing policy in a competitive market. Figure 4 presents the findings. First, when consumers' intrinsic valuation of the product is relatively low (e.g., when $v_{1}=0.2$ ), the optimal second-period price increases with the SL intensity. When the SL intensity is higher than a certain level, the optimal first-period price also increases with the SL intensity. The intuition is that when SL can significantly increase potential customers' adoption intention, firms can charge higher prices. In addition, we find that when disclosed sales quantities and SL can significantly increase consumers' acceptance of the new product or technology, the firms may adopt an increasingpricing strategy in the competitive market. However, if consumers' initial intrinsic valuation of the product is already high enough (e.g., when $\left.v_{1}=0.6\right)$, stronger SL would result in consumers' higher enthusiasm for the product and intensify the harmful competition between the two firms. In this case, the firms have to lower prices with an increase in SL intensity.

We also numerically demonstrate how SL impacts the total social welfare in a competitive market. The results are presented in Figure 5. In this numerical example, we still use $N=100$. Similar to the impact of SL on a firm's total profit, 


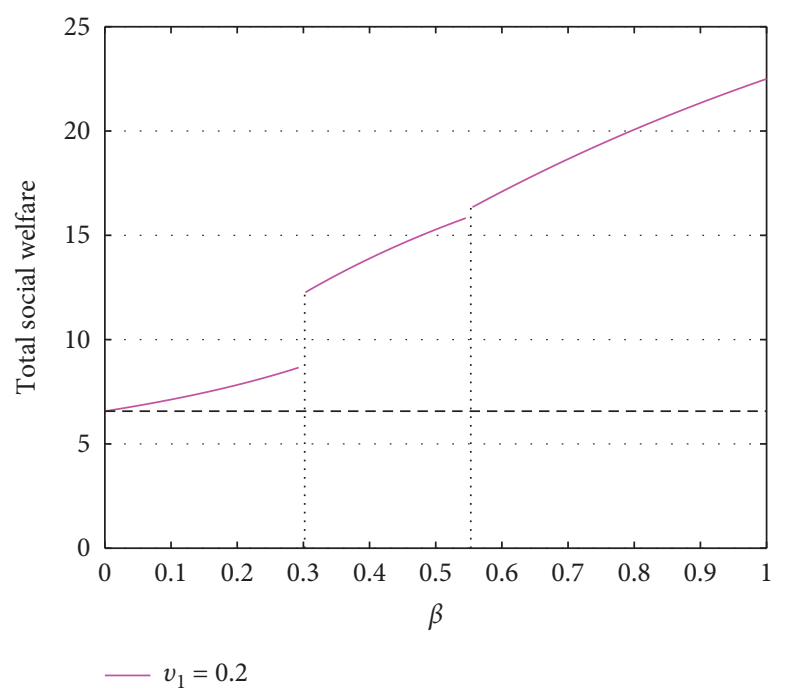

(a)

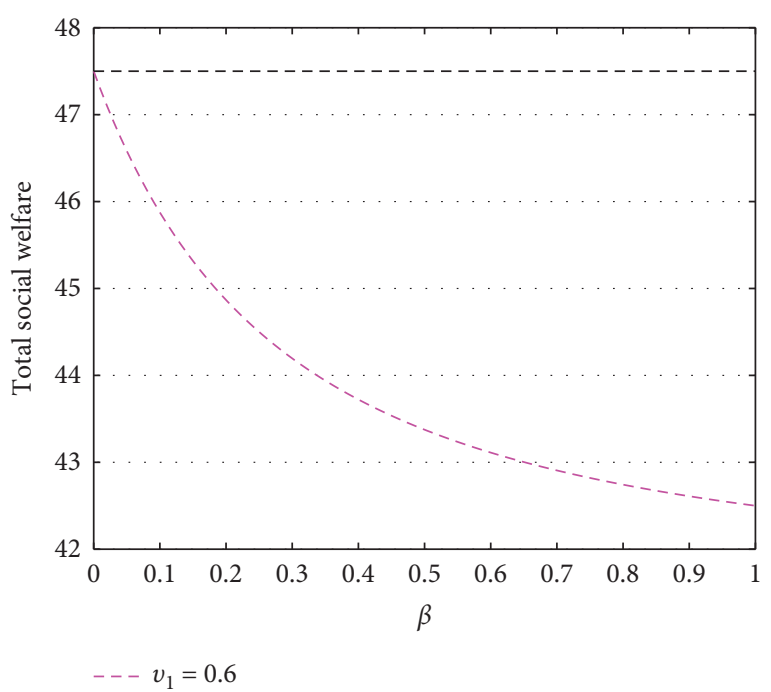

(b)

Figure 5: The total social welfare w.r.t. $\beta$ in a duopoly market.

we can see that when consumers' intrinsic valuation of the product is relatively low (e.g., when $v_{1}=0.2$ ), disclosing initial sales quantities and inducing consumers to learn are beneficial for the total social welfare. However, if consumers' intrinsic valuation of the product is relatively high (e.g., when $v_{1}=0.6$ ), SL effect intensifies competition between the firms, which is harmful to the total social welfare.

\section{Conclusion}

Sales disclosure and SL have different impacts on firms' profits in different market contexts. Disclosing sales quantities and enhancing the intensity of SL are always beneficial for a monopoly firm. A monopoly firm can control its initial sales by lowering the launch price, further influencing consumer SL outcomes. We demonstrate that when historical sales quantities can influence potential customers' purchase intentions, a monopoly firm should decrease its profit margin and adopt a mass pricing policy. By leveraging high sales quantities to attract more buyers, the firm can achieve great profit through a high market penetration rate. For example, some retailers on the Taobao platform often set low initial prices to accumulate high historical sales quantities, which further attracts potential customers to purchase their products. For consumers, when the impact intensity of historical sales quantities on their product valuations is lower than a certain level, consumer learning based on historical sales makes a monopoly firm decrease its price, which increases consumer surplus. However, if historical sales quantities strongly drive consumers' purchase intention, the firm may take advantage of SL and increase its product price, which would harm consumers. Overall, in a monopoly market, disclosing sales quantities leads to firms setting lower prices and more consumers purchasing the product, which is beneficial for total social welfare.
However, disclosing sales quantities in the presence of SL is a double-edged sword in a competitive market. On the one hand, disclosing historical sales in the presence of SL may increase consumers' willingness to pay for a product and attract more customers to adopt it. On the other hand, when consumers' valuation of a product increases, the market becomes more competitive. Thus, in a competitive market, firms can release their sales quantities when consumers' intrinsic valuation of a product is relatively low. Specifically, in an early stage of a product launch, when many potential customers have a relatively low purchase intention for the product, total sales quantities disclosed by competing firms may increase consumers' acceptance of a new product or technology and benefit both firms. However, in a later stage, when consumers' intrinsic valuation for the product is already high enough, firms should not disclose sales quantities or induce SL. This finding is consistent with the findings of Jiang and Wang [17] who prove that a higher product rating is always beneficial for a monopoly firm while it may intensify competition between competitive firms and be harmful. Our findings also extend the results in Sun et al.'s paper [7] which demonstrate that SL always harms firms in competitive markets.

Our study has systematically analyzed the role of sales disclosure and SL on firms' pricing policies, profits, and total social welfare. We shed light on how consumers' observational learning based on historical sales quantities interacts with firms' operational strategies. We also expanded the understanding of the impact of SL on firms' pricing policy and profit in a competitive market. In the model, we did not consider consumers' strategic delay behavior for waiting for historical sales information. Some related literature has demonstrated that in the presence of SL, consumers' strategic delay of their consumption often harms firms' profits. Exploring firms' optimal information disclosure policy in a competitive market by considering consumers' strategic choice of their consumption time is a possible future 
research direction. It is also meaningful to empirically verify the impacts of disclosed historical sales and SL in competitive markets.

\section{Appendix}

\section{Proofs}

Proof of Proposition 1. (i) The Optimal Prices and Profit. The firm's profit function is

$$
\Pi(\alpha)= \begin{cases}N\left[\alpha(1-\alpha)+\frac{(1-\beta+(2 \beta-1) \alpha)^{2}}{4(1-\beta)}\right] & \text { if } 0 \leq \alpha \leq 1-\beta, \\ N \alpha(1-\alpha)(1+\beta) & \text { if } 1-\beta<\alpha \leq 1 .\end{cases}
$$

Case (1): when $0 \leq \alpha \leq 1-\beta . \quad(\partial \Pi / \partial \alpha)=N$ $\left[\left(1+\beta-2 \beta^{2}\right)+\left(4 \beta^{2}-3\right) \alpha / 2(1-\beta)\right]$ and $\left(\partial^{2} \Pi / \partial \alpha^{2}\right)=$ $\left(N\left(4 \beta^{2}-3\right) \alpha / 2(1-\beta)\right)$. If $4 \beta^{2}-3 \leq 0$, namely, when $0 \leq \beta<(\sqrt{3} / 2)$, then $\Pi$ is a concave function $\alpha$. By letting $(\partial \Pi / \partial \alpha)=0$, we obtain $\quad \alpha=(1+$ $\left.\beta-2 \beta^{2} / 3-4 \beta^{2}\right)$. If $\left(1+\beta-2 \beta^{2} / 3-4 \beta^{2}\right) \leq 1-\beta$, then $\alpha^{*}=\left(1+\beta-2 \beta^{2} / 3-4 \beta^{2}\right)$; otherwise, $\quad \alpha^{*}=1-\beta$. Condition $\left(1+\beta-2 \beta^{2} / 3-4 \beta^{2}\right) \leq 1-\beta$ is equivalent to $(2 \beta-1)\left(\beta^{2}-1\right) \geq 0$. Therefore, (i) if $0 \leq \beta \leq(1 / 2)$, then on interval $[0,1-\beta], \Pi$ is a concave function of $\alpha$ which reaches maximum at point $\alpha=(1+\beta-$ $\left.2 \beta^{2} / 3-4 \beta^{2}\right)$; (ii) if $(1 / 2)<\beta \leq(\sqrt{3} / 2)$, then $\Pi$ is a concave and increasing function of $\alpha$ which reaches maximum at point $\alpha=1-\beta$; (iii) if $(\sqrt{3} / 2) \leq \beta \leq 1$, then $\Pi$ is a convex and increasing function of $\alpha$ which reaches maximum at point $\alpha=1-\beta$.
Case (2): when $1-\beta<\alpha \leq 1 .(\partial \Pi / \partial \alpha)=N(1-2 \alpha)(1+$ $\beta$ ) and $\left(\partial^{2} \Pi / \partial \alpha^{2}\right)<0$. It is straightforward to derive that (i) if $0 \leq \beta \leq(1 / 2)$, then on interval $(1-\beta, 1]$, $\Pi$ decreases with $\alpha$ and reaches maximum when $\alpha=1-\beta$. (ii) If $(1 / 2)<\beta \leq 1$, then $\Pi$ is a concave function of $\alpha$ which reaches maximum when $\alpha=(1 / 2)$.

Combining the result in Case (1) and Case (2), we obtain that (i) if $0 \leq \beta \leq(1 / 2)$, then $\alpha^{*}=\left(1+\beta-2 \beta^{2} / 3-4 \beta^{2}\right)$, $p_{1}^{*}=1-\alpha^{*}=\left(2-\beta-2 \beta^{2} / 3-4 \beta^{2}\right), \quad p_{2}^{*}=(1-\beta+(2 \beta-$ 1) $\left.\alpha^{*} / 2\right)=\left(1-\beta / 3-4 \beta^{2}\right)$, and $\Pi^{*}=\left(N\left(1-\beta^{2}\right) / 3-4 \beta^{2}\right)$; if $(1 / 2)<\beta \leq 1$, then $\alpha^{*}=(1 / 2), \quad p_{1}^{*}=1-\alpha^{*}=(1 / 2)$, $p_{2}^{*}=\beta \alpha^{*}=(\beta / 2)$, and $\Pi^{*}=(N(1+\beta) / 4)$.

(ii) Properties of the Optimal Prices and Profit.

$$
\begin{gathered}
\frac{\partial p_{1}^{*}}{\partial \beta} \\
\frac{\partial p_{2}^{*}}{\partial \beta}= \begin{cases}\frac{-3+8 \beta-4 \beta^{2}}{\left(3-4 \beta^{2}\right)^{2}} & \text { if } 0 \leq \beta \leq \frac{1}{2}, \\
\frac{1}{2} & \text { if } \frac{1}{2}<\beta \leq 1,\end{cases} \\
\frac{\partial \Pi^{*}}{\partial \beta}= \begin{cases}\frac{2 N \beta}{\left(3-4 \beta^{2}\right)^{2}} & \text { if } 0 \leq \beta \leq \frac{1}{2}, \\
\frac{N}{4} & \text { if } \frac{1}{2}<\beta \leq 1,\end{cases} \\
p_{1}^{*}-p_{2}^{*}= \begin{cases}\frac{1-2 \beta^{2}}{3-4 \beta^{2}} & \text { if } 0 \leq \beta \leq \frac{1}{2}, \\
\frac{1-\beta}{2} & \text { if } \frac{1}{2}<\beta \leq 1 .\end{cases}
\end{gathered}
$$


When $0 \leq \beta \leq(1 / 2), \quad\left(\partial p_{1}^{*} / \partial \beta\right)<0 \quad$ and $\quad\left(\partial p_{2}^{*} / \partial \beta\right)<0$, namely, $p_{1}^{*}$ and $p_{2}^{*}$ decrease with $\beta$. When $(1 / 2)<\beta \leq 1$, $p_{1}^{*}$ keeps constant with $\beta$ and $p_{2}^{*}$ increases with $\beta$. For $\beta \in(0,1)$, $\left(\partial \Pi^{*} / \partial \beta\right)>0$, namely, $\Pi^{*}$ increases with $\beta$. Finally, it is easy to show that $p_{1}^{*}-p_{2}^{*} \geq 0$ always holds.

\section{Proof of Proposition 2.}

Case (1): when $\beta \in[0,(1 / 2)]$,

$$
\frac{\partial C S}{\partial \beta}=\frac{-N\left(-3+5 \beta+6 \beta^{2}-20 \beta^{3}+8 \beta^{4}\right)}{\left(3-4 \beta^{2}\right)^{3}} .
$$

Let $g(\beta)=-3+5 \beta+6 \beta^{2}-20 \beta^{3}+8 \beta^{4}$, and we have $g^{\prime}(\beta)=5+12 \beta-60 \beta^{2}+32 \beta^{3}, \quad g^{\prime \prime}(\beta)=12 \beta-120 \beta+$ $96 \beta^{2}$. For $\beta \in[0,1 / 2], g^{\prime \prime}(\beta) \leq\left. g^{\prime \prime}(\beta)\right|_{\beta=0}=0$, which means that $g^{\prime}(\beta)$ decreases with $\beta$. Therefore, $g^{\prime}(\beta) \geq\left. g^{\prime}(\beta)\right|_{\beta=(1 / 2)}=0$, which means that $g(\beta)$ is a non-decreasing function of $\beta$. It follows $g(\beta) \leq$ $\left.g(\beta)\right|_{\beta=(1 / 2)}=-1$. We obtain that $(\partial \mathrm{CS} / \partial \beta)=$ $\left(-N g(\beta) /\left(3-4 \beta^{2}\right)^{3}\right)>0$ always holds. It means that the total consumer surplus is increasing in $\beta$.

$$
\frac{\partial W}{\partial \beta}=\frac{N\left(3+\beta-6 \beta^{2}+12 \beta^{3}-8 \beta^{4}\right)}{\left(3-4 \beta^{2}\right)^{3}} .
$$

Let $f(\beta)=3+\beta-6 \beta^{2}+12 \beta^{3}-8 \beta^{4}$, and we have $f^{\prime}(\beta)=1-12 \beta+36 \beta^{2}-32 \beta^{3}, \quad f^{\prime \prime}(\beta)=-12+72 \beta-$ $96 \beta^{2}$. By letting $f^{\prime \prime}(\beta)=0$, we obtain that $\beta=(1 / 4)$ or $\beta=(1 / 2)$. It follows for $\beta \in[0,(1 / 4)], f^{\prime \prime}(\beta) \leq 0$ and for $\beta \in((1 / 4),(1 / 2)), f^{\prime \prime}(\beta) \geq 0$. Therefore, on interval $[0,(1 / 4)], f^{\prime}(\beta)$ decreases with $\beta$, while on interval $((1 / 4),(1 / 2)], \quad f^{\prime}(\beta)$ increases with $\beta$. By letting $f^{\prime}(\beta)=0$, we obtain that $\beta=(1 / 8)$ or $\beta=(1 / 2)$. Therefore, on interval $[0,(1 / 8)], f^{\prime}(\beta)>0$, and on interval $((1 / 8),(1 / 2)], f^{\prime}(\beta)<0$. It means that $f(\beta)$ first increases and then decreases with $\beta$. We have $f(\beta) \geq \min (f(0), f(1 / 2))=\min (3,3)>0$. Therefore, $(\partial W / \partial \beta)=\left(N f(\beta) /\left(3-4 \beta^{2}\right)^{3}\right)>0$ which is equivalent to the fact that $W$ increases with $\beta$.

Case (2): when $\beta \in((1 / 2), 1]$. On this interval, it is straightforward to check that CS decreases with $\beta$, while $W$ increases with $\beta$.
Proof of Lemma 1.

Case (1): when the market is uncovered. In this case, for firm $\mathrm{A}$, there exists a threshold of $x$, denoted by $x_{A}$, which satisfies $u_{2 A}=v_{2}-(1 / 2) x_{A}-p_{2 A}=0$. It follows $x_{A}=2\left(v_{2}-p_{2 A}\right)$. Firm A's optimization problem is

$$
\text { s.t. } p_{2 A} \geq 0,2\left(v_{2}-p_{2 A}\right) \leq \frac{1}{2}, 2\left(v_{2}-p_{2 A}\right) \geq \alpha_{A} \text {. }
$$

Based on the first order condition, we obtain $p_{2 A}=\left(v_{2}-\left(\alpha_{A} / 2\right) / 2\right)$. (i) If $v_{2}-\left(\alpha_{A} / 2\right) \leq 0$, then $p_{2 A}^{*}=0$. (ii) If $\quad\left(v_{2}-\left(\alpha_{A} / 2\right) / 2\right)>0 \quad$ and $v_{2}-\left(v_{2}-\left(\alpha_{A} / 2\right) / 2\right) \leq(1 / 4), \quad$ namely, when $\left(\alpha_{A} / 2\right)<v_{2} \leq\left(1-\alpha_{A} / 2\right)$, then $p_{2 A}^{*}=\left(v_{2}-\left(\alpha_{A} / 2\right) / 2\right)$. Combining the results, we have that when $0 \leq v_{2} \leq\left(1-\alpha_{A} / 2\right), \quad p_{2 A}^{*}=\left(\left[v_{2}-\left(\alpha_{A} / 2\right)\right]^{+} / 2\right) \quad$ and $\Pi_{2 A}^{*}=\left(N\left(\left[v_{2}-\left(\alpha_{A} / 2\right)\right]^{+}\right)^{2} / 4\right)$.

Case (2): when the market is covered. The indifferent point satisfies

$$
u_{2 A}=v_{2}-\frac{1}{2} \bar{x}-p_{2 A}=v_{2}-\frac{1}{2}(1-\bar{x})-p_{2 B} .
$$

Firm A's optimization problem is

$$
\text { s.t. } p_{2 A} \geq 0, v_{2}-\frac{1}{2} \cdot \frac{1}{2}-p_{2 A} \geq 0 \text {. }
$$

Based on the first order condition, we obtain $p_{2 A}=(1 / 2)-\alpha_{A}$. If $\quad v_{2}-(1 / 4)-(1 / 2)+\alpha_{A} \geq 0$, namely, when $v_{2} \geq(3 / 4)-\alpha_{A}$, then $p_{2 A}^{*}=(1 / 2)-\alpha_{A}$ and $\Pi_{2 A}^{*}=N p_{2 A}^{*}\left(\bar{x}^{*}-\alpha_{A}\right)=N\left((1 / 2)-\alpha_{A}\right)^{2}$.

Case (3): when $\left(1-\alpha_{A} / 2\right)<v_{2}<(3 / 4)-\alpha_{A}$ (the market is covered). The optimal prices satisfies $v_{2}-(1 / 2) \cdot(1 / 2)-p_{2 A}^{*}=0$, namely, $p_{2 A}^{*}=v_{2}-(1 / 4)$. In this case, $\Pi_{2 A}^{*}=N p_{2 A}^{*}\left((1 / 2)-\alpha_{A}\right)=$ $N\left(v_{2}-(1 / 4)\right)\left((1 / 2)-\alpha_{A}\right)$.

Proof of Proposition 3.

(1) When $0 \leq \beta<(1 / 4)$.

Scenario (1-1): when $0 \leq v_{1}<((1 / 2)-2 \beta / 2(1-\beta))$.

$$
\begin{aligned}
\Pi_{A}\left(\alpha_{A}\right) \\
\frac{\partial \Pi_{A}}{\partial \alpha_{A}}=N\left(v_{1}-\alpha_{A}+\frac{\left[2 \beta \alpha_{A}+(1-\beta) v_{1}-(1 / 2) \alpha_{A}\right](2 \beta-(1 / 2))}{2}\right) \\
\frac{\partial^{2} \Pi_{A}}{\partial \alpha_{A}^{2}}=N\left(2 \beta^{2}-\beta-\frac{7}{8}\right) .
\end{aligned}
$$


It is easy to check that when $0 \leq \beta<(1 / 4)$, $\left(\partial^{2} \Pi_{A} / \partial \alpha_{A}^{2}\right)<0$, namely, $\Pi_{A}$ is a concave function of $\alpha_{A}$. By letting $\left(\partial \Pi_{A} / \partial \alpha_{A}\right)=0$, we can obtain $\alpha_{A}=\left(2 v_{1}+(1-\beta) v_{1} \quad(2 \beta-(1 / 2)) / 2-(2 \beta-(1 /\right.$

$2))^{2}$ ). It is easy to check that when $0 \leq \beta<(1 / 4)$, $0<\left(2 v_{1}+(1-\beta) v_{1}(2 \beta-(1 / 2)) / 2-(2 \beta-(1 / 2))^{2}\right)$ $<(1 / 2)$. Therefore, in this scenario, $\alpha_{A}^{*}=$ $\left(2\left(3+5 \beta-4 \beta^{2}\right) v_{1} / 7+8 \beta-16 \beta^{2}\right), \quad p_{1}^{*}=v_{1}-(1 /$ 2) $\alpha_{A}^{*}=\left(\left(4+3 \beta-12 \beta^{2}\right) v_{1} / 7+8 \beta-16 \beta^{2}\right), \quad p_{2 A}^{*}=$ $\left(\tilde{v}_{1}-(1 / 2) \alpha_{A}^{*} / 2\right)=\left(2(1+2 \beta) v_{1} / 7+8 \beta-16 \beta^{2}\right)$, and $\Pi_{A}^{*}=\left(2 N\left(2+3 \beta-3 \beta^{2}\right) v_{1}^{2} / 7+8 \beta-16 \beta^{2}\right)$.

Scenario $(1-2)$ : when $\quad((1 / 2)-2 \beta / 2(1-\beta)) \leq$ $v_{1}<(1 / 2(1-\beta))$. In this scenario, $0<(1-2(1-$ $\left.\beta) v_{1} / 1+4 \beta\right) \leq\left(3-4(1-\beta) v_{1} / 4+8 \beta\right) \leq(1 / 2)$, and

$$
\Pi_{A}\left(\alpha_{A}\right)= \begin{cases}g_{1}\left(\alpha_{A}\right)=N\left(v_{1}-\frac{1}{2} \alpha_{A}\right) \alpha_{A}+N\left[2 \beta \alpha_{A}+(1-\beta) v_{1}-\frac{1}{2} \alpha_{A}\right]^{2} / 4, & \text { if } 0 \leq \alpha_{A}<\frac{1-2(1-\beta) v_{1}}{1+4 \beta} ; \\ g_{2}\left(\alpha_{A}\right)=N\left(v_{1}-\frac{1}{2} \alpha_{A}\right) \alpha_{A}+N\left[2 \beta \alpha_{A}+(1-\beta) v_{1}-\frac{1}{4}\right]\left(\frac{1}{2}-\alpha_{A}\right), & \text { if } \frac{1-2(1-\beta) v_{1}}{1+4 \beta} \leq \alpha_{A}<\frac{3-4(1-\beta) v_{1}}{4+8 \beta} ; \\ g_{3}\left(\alpha_{A}\right)=N\left(v_{1}-\frac{1}{2} \alpha_{A}\right) \alpha_{A}+N\left(\frac{1}{2}-\alpha_{A}\right)\left(\frac{1}{2}-\alpha_{A}\right), & \text { if } \frac{3-4(1-\beta) v_{1}}{4+8 \beta} \leq \alpha_{A} \leq \frac{1}{2} .\end{cases}
$$

In this scenario, $\Pi_{A}\left(\alpha_{A}\right)$ is a piecewise and continuous function of $\alpha_{A}$. By comparing the optimal profits on the three intervals, we can obtain the optimal $\alpha_{k 1}^{*}$.
Scenario $\quad(1-3)$ : when $\quad(1 / 2(1-\beta)) \leq v_{1}<(3 / 4$ $(1-\beta))$. In this scenario, $\left(1-2(1-\beta) v_{1} / 1+\right.$ $4 \beta) \leq 0<\left(3-4(1-\beta) v_{1} / 4+8 \beta\right) \leq(1 / 2)$, and

$$
\Pi_{A}\left(\alpha_{A}\right)= \begin{cases}g_{2}\left(\alpha_{A}\right)=N\left(v_{1}-\frac{1}{2} \alpha_{A}\right) \alpha_{A}+N\left[2 \beta \alpha_{A}+(1-\beta) v_{1}-\frac{1}{4}\right]\left(\frac{1}{2}-\alpha_{A}\right), & \text { if } 0 \leq \alpha_{A}<\frac{3-4(1-\beta) v_{1}}{4+8 \beta} ; \\ g_{3}\left(\alpha_{A}\right)=N\left(v_{1}-\frac{1}{2} \alpha_{A}\right) \alpha_{A}+N\left(\frac{1}{2}-\alpha_{A}\right)\left(\frac{1}{2}-\alpha_{A}\right), & \text { if } \frac{3-4(1-\beta) v_{1}}{4+8 \beta} \leq \alpha_{A} \leq \frac{1}{2}\end{cases}
$$

Define Foc ${ }_{1}$ which satisfies $\left(\partial g_{2}\left(\alpha_{A}\right) /\right.$ $\left.\partial \alpha_{A}\right)\left.\right|_{\alpha_{A}=F_{0} c_{1}}=0$, and we obtain that Foc $_{1}=$ $\left(\beta\left(1+v_{1}\right)+(1 / 4) / 1+4 \beta\right)$. It is easy to prove that $g_{2}\left(\alpha_{A}\right)$ is a concave function of $\alpha_{A}$ and $g_{3}\left(\alpha_{A}\right)$ is a convex function of $\alpha_{A}$. SinceFoc $1-(3-4(1-\beta)$ $\left.v_{1} / 4+8 \beta\right)=-\left(4 \beta^{2}\left(v_{1}-1\right)+\beta\left(3-8 v_{1}\right)+1-2 v_{1} /\right.$ $2(1+2 \beta)(1+4 \beta))$, it is easy to check that for any
$0 \leq \beta \leq 1, \quad$ Foc $_{1} \geq\left(3-4(1-\beta) v_{1} / 4+8 \beta\right) \quad$ always holds. It means that on interval $\left[0,\left(3-4(1-\beta) v_{1} / 4+8 \beta\right)\right), \Pi_{A}$ is an increasing function of $\alpha_{A}$. Therefore, we can derive the optimal $\alpha_{A}$ by comparing $\left.\Pi_{A}\left(\alpha_{A}\right)\right|_{\alpha_{A}=\left(3-4(1-\beta) v_{1} / 4+8 \beta\right)}$ and $\left.\Pi_{A}\left(\alpha_{A}\right)\right|_{\alpha_{A}=(1 / 2)}$.

$$
\left.\Pi_{A}\left(\alpha_{A}\right)\right|_{\alpha_{A}=\left(3-4(1-\beta) v_{1} / 4+8 \beta\right)}-\left.\Pi_{A}\left(\alpha_{A}\right)\right|_{\alpha_{A}=(1 / 2)}=\frac{N\left(1-4 \beta-4 v_{1}+4 \beta v_{1}\right)\left(-3-12 \beta+4 v_{1}+20 \beta v_{1}\right)}{32(1+2 \beta)^{2}} .
$$

By solving equation $\left(1-4 \beta-4 v_{1}+\right.$ $\left.4 \beta v_{1}\right)\left(-3-12 \beta+4 v_{1}+20 \beta v_{1}\right)=0$, we obtain $v_{1}=$ $(1-4 \beta / 4(1-\beta))$ or $v_{1}=(3(1+4 \beta) / 4(1+5 \beta))$. In addition, the coefficient of $\left(v_{1}\right)^{2}$ is $16(5 \beta+1)(\beta-$ $1)$ which is non-positive. First, it is easy to check that $(1-4 \beta / 4(1-\beta))<(1 / 2(1-\beta))$. Second,

$$
\frac{3(1+4 \beta)}{4(1+5 \beta)}-\frac{1}{2(1-\beta)}=\frac{(1-4 \beta)(1+3 \beta)}{4(1+5 \beta)(1-\beta)} \text {. }
$$

We have (i) when $(1 / 2(1-\beta)) \leq v_{1}<$ $(3(1+4 \beta) / 4(1+5 \beta)),\left.\quad \Pi_{A}\left(\alpha_{A}\right)\right|_{\alpha_{A}=\left(3-4(1-\beta) v_{1} / 4+8 \beta\right)^{-}}$ $\left.\Pi_{A}\left(\alpha_{A}\right)\right|_{\alpha_{A}=(1 / 2)}>0$. Therefore, $\alpha_{A}^{*}=(3-4(1-$ B) $\left.v_{1} / 4+8 \beta\right), \quad p_{1 A}^{*}=v_{1}-(1 / 2) \alpha_{A}^{*}=\left(3\left[4(1+\beta) v_{1}-\right.\right.$ 1] $/ 8+16 \beta), \quad p_{2 A}^{*}=(1 / 2)-\alpha_{A}^{*}=\left(4(1-\beta) v_{1}+4 \beta-\right.$ $1 / 4+8 \beta)$. (ii) When $(3(1+4 \beta) / 4(1+5 \beta)) \leq$ $v_{1}<(3 / 4(1-\beta)),\left.\quad \Pi_{A}\left(\alpha_{A}\right)\right|_{\alpha_{A}=\left(3-4(1-\beta) v_{1} / 4+8 \beta\right)}-\Pi_{A}$ $\left.\left(\alpha_{A}\right)\right|_{\alpha_{A}=(1 / 2)} \leq 0$. Therefore, $\quad \alpha_{A}^{*}=(1 / 2)$. 
$p_{1 A}^{*}=v_{1}-(1 / 2) \alpha_{A}^{*}=v_{1}-(1 / 4), \quad$ and
Scenario (1-4): when $(3 / 4(1-\beta)) \leq v_{1} \leq 1$. In this scenario, $\quad\left(1-2(1-\beta) v_{1} / 1+4 \beta\right) \leq(3-4(1-\beta)$ $\left.v_{1} / 4+8 \beta\right) \leq 0$. We have

$$
\begin{gathered}
\Pi_{A}\left(\alpha_{A}\right) \\
\frac{\partial \Pi_{A}}{\partial \alpha_{A}}=N\left(v_{1}+\alpha_{A}-1\right), \\
\frac{\partial^{2} \Pi_{A}}{\partial \alpha_{A}^{2}}=N
\end{gathered}
$$

$\Pi_{A}\left(\alpha_{A}\right)$ is a convex function of $\alpha_{A}$. For $(3 / 4(1-\beta)) \leq v_{1} \leq 1$,

$\Pi_{A}(1 / 2)-\Pi_{A}(0)=v_{1}-(3 / 8)>0$. Therefore, in this scenario, $\alpha_{A}^{*}=(1 / 2), p_{1 A}^{*}=v_{1}-(1 / 4)$, and $\Pi_{A}^{*}=\left(N\left(4 v_{1}-1\right) / 8\right)$.

(2) When $(1 / 4) \leq \beta<1$.
Scenario (2-1): when $0 \leq v_{1}<(1 / 2(1-\beta))$. In this scenario,

$0<\left(1-2(1-\beta) v_{1} / 1+4 \beta\right) \leq\left(3-4(1-\beta) v_{1}\right.$

$/ 4+8 \beta) \leq(1 / 2)$, we have

$$
\Pi_{A}\left(\alpha_{A}\right)= \begin{cases}N\left(v_{1}-\frac{1}{2} \alpha_{A}\right) \alpha_{A}+N\left[2 \beta \alpha_{A}+(1-\beta) v_{1}-\frac{1}{2} \alpha_{A}\right]^{2} / 4, & \text { if } 0 \leq \alpha_{A}<\frac{1-2(1-\beta) v_{1}}{1+4 \beta} \\ N\left(v_{1}-\frac{1}{2} \alpha_{A}\right) \alpha_{A}+N\left[2 \beta \alpha_{A}+(1-\beta) v_{1}-\frac{1}{4}\right]\left(\frac{1}{2}-\alpha_{A}\right), & \text { if } \frac{1-2(1-\beta) v_{1}}{1+4 \beta} \leq \alpha_{A}<\frac{3-4(1-\beta) v_{1}}{4+8 \beta} \\ N\left(v_{1}-\frac{1}{2} \alpha_{A}\right) \alpha_{A}+N\left(\frac{1}{2}-\alpha_{A}\right)\left(\frac{1}{2}-\alpha_{A}\right), & \text { if } \frac{3-4(1-\beta) v_{1}}{4+8 \beta} \leq \alpha_{A} \leq \frac{1}{2}\end{cases}
$$

In this scenario, $\Pi_{A}\left(\alpha_{A}\right)$ is a piecewise and continuous function of $\alpha_{A}$. By comparing the optimal profits on the three intervals, we can obtain the optimal $\alpha_{k 2}^{*}$.
Scenario (2-2): when $\quad(1 / 2(1-\beta)) \leq v_{1}<$ $(3 / 4(1-\beta))$. In this scenario, $\left(1-2(1-\beta) v_{1} /\right.$ $1+4 \beta) \leq 0<\left(3-4(1-\beta) v_{1} / 4+8 \beta\right) \leq(1 / 2)$, and

$$
\Pi_{A}\left(\alpha_{A}\right)= \begin{cases}g_{2}\left(\alpha_{A}\right)=N\left(v_{1}-\frac{1}{2} \alpha_{A}\right) \alpha_{A}+N\left[2 \beta \alpha_{A}+(1-\beta) v_{1}-\frac{1}{4}\right]\left(\frac{1}{2}-\alpha_{A}\right), & \text { if } 0 \leq \alpha_{A}<\frac{3-4(1-\beta) v_{1}}{4+8 \beta} \\ g_{3}\left(\alpha_{A}\right)=N\left(v_{1}-\frac{1}{2} \alpha_{A}\right) \alpha_{A}+N\left(\frac{1}{2}-\alpha_{A}\right)\left(\frac{1}{2}-\alpha_{A}\right), & \text { if } \frac{3-4(1-\beta) v_{1}}{4+8 \beta} \leq \alpha_{A} \leq \frac{1}{2}\end{cases}
$$

Similar to the analysis in Scenario (1-3), we can prove that $g_{2}\left(\alpha_{A}\right)$ is a concave and increasing function of $\alpha_{A}$ and $g_{3}\left(\alpha_{A}\right)$ is a convex function of
$\alpha_{A}$. Therefore, we can derive the optimal $\alpha_{A}$ by comparing $\left.\Pi_{A}\left(\alpha_{A}\right)\right|_{\alpha_{A}=\left(3-4(1-\beta) v_{1} / 4+8 \beta\right)}$ and $\left.\Pi_{A}\left(\alpha_{A}\right)\right|_{\alpha_{A}=(1 / 2)}$.

$$
\left.\Pi_{A}\left(\alpha_{A}\right)\right|_{\alpha_{A}=\left(3-4(1-\beta) v_{1} / 4+8 \beta\right)}-\Pi_{A}\left(\alpha_{A}\right)_{\alpha_{A}=(1 / 2)}=\frac{N\left(1-4 \beta-4 v_{1}+4 \beta v_{1}\right)\left(-3-12 \beta+4 v_{1}+20 \beta v_{1}\right)}{32(1+2 \beta)^{2}} .
$$


By solving equation $\left(1-4 \beta-4 v_{1}+4 \beta v_{1}\right)(-3-$ $\left.12 \beta+4 v_{1}+20 \beta v_{1}\right)=0$, we obtain $v_{1}=(1-$ $4 \beta / 4(1-\beta))$ or $v_{1}=(3(1+4 \beta) / 4(1+5 \beta))$; in addition, the coefficient of $\left(v_{1}\right)^{2}$ is $16(5 \beta+1)(\beta-1)$ which is non-positive.

$$
\frac{3(1+4 \beta)}{4(1+5 \beta)}-\frac{1}{2(1-\beta)}=\frac{(1-4 \beta)(1+3 \beta)}{4(1+5 \beta)(1-\beta)}<0 .
$$

It is easy to check that $(1-4 \beta / 4(1-$ $\beta))<(1 / 2(1-\beta))$ and $(3(1+4 \beta) / 4(1+5 \beta))<$ $(1 / 2(1-\beta))$; therefore, on interval $[(1 / 2(1-\beta)),(3 / 4(1-\beta)))$, we always have $\left.\Pi_{A}\left(\alpha_{A}\right)\right|_{\alpha_{A}=\left(3-4(1-\beta) v_{1} / 4+8 \beta\right)}-\Pi_{A}\left(\alpha_{A}\right)_{\alpha_{A}=(1 / 2)}<0$. We obtain that $\alpha_{A}^{*}=(1 / 2), \quad p_{1 A}^{*}=v_{1}-(1 / 4)$, and $\Pi_{A}^{*}=\left(N\left(4 v_{1}-1\right) / 8\right)$.

Scenario (2-3): similar to the analysis in Scenario (1-4), we can obtain that $\alpha_{A}^{*}=(1 / 2), p_{1 A}^{*}=v_{1}-$ $(1 / 4)$ and $\Pi_{A}^{*}=\left(N\left(4 v_{1}-1\right) / 8\right)$.

$$
\begin{aligned}
& \text { Proof of Proposition 4. (i) When } \\
& \qquad \begin{array}{l}
4(1-\beta)), \\
\frac{\partial \Pi_{k}^{*}}{\partial \beta}
\end{array}
\end{aligned}
$$

Define $h(\beta)=37-58 \beta-216 \beta^{2}+192 \beta^{3}$. We have $h^{\prime}(\beta)=-58-432 \beta+576 \beta^{2}, h^{\prime \prime}(\beta)=-432+1152 \beta$. It is easy to check that for $\beta \in[0,(1 / 4)], h^{\prime \prime}(\beta)<0$. It means that $h^{\prime}(\beta)$ decreases with $\beta$. It follows $h^{\prime}(\beta) \leq\left. h^{\prime}(\beta)\right|_{\beta=0}=-58<0$. Therefore, $h(\beta)$ decreases with $\beta$. We obtain that $h(\beta) \geq$ $\left.h(\beta)\right|_{\beta=(1 / 4)}=12>0$. Thus, when $0 \leq v_{1}<(1-$ $4 \beta / 4(1-\beta))$ and $0 \leq \beta \leq(1 / 4), \quad\left(\partial \Pi_{k}^{*} / \partial \beta\right)=(2 N h$ $\left.(\beta) /\left(7+8 \beta-16 \beta^{2}\right)^{2}\right)>0$ always holds. It means that $\Pi_{k}^{*}$ increases with $\beta$.

(ii) When $(1 / 2(1-\beta)) \leq v_{1}<(3(1+4 \beta) / 4(1+5 \beta))$.

$$
\frac{\partial \Pi_{k}^{*}}{\partial \alpha_{k}^{*}}=N\left(v_{1}-1+\alpha_{k}^{*}\right)=\frac{N\left(-1-8 \beta+12 \beta v_{1}\right)}{(4+8 \beta)} \text {. }
$$

Since $-1-8 \beta+12 \beta v_{1}<-1-8 \beta+12 \beta \cdot(3(1+4 \beta$ )$/ 4(1+5 \beta))=\left(-(1+2 \beta)^{2} / 1+5 \beta\right)<0$, it means that $\Pi_{k}^{*}$ decreases with $\alpha_{k}^{*}$.

$$
\frac{\partial \alpha_{k}^{*}}{\partial \beta}=\frac{48 v_{1}-24}{(4+8 \beta)^{2}} \text {. }
$$

When $v_{1}<(1 / 2),\left(\partial \alpha_{k}^{*} / \partial \beta\right)<0$, which means that $\alpha_{k}^{*}$ decreases with $\beta$. Therefore, on this interval, $\Pi_{k}^{*}$ increases with $\beta$. When $v_{1} \geq(1 / 2),\left(\partial \alpha_{k}^{*} / \partial \beta\right) \geq 0$ and $\alpha_{k}^{*}$ increases with $\beta$. It follows that $\Pi_{k}^{*}$ decreases with $\beta$.

\section{Data Availability}

No data were used to support this study.

\section{Conflicts of Interest}

The authors declare that there are no conflicts of interest regarding the publication of this paper.

\section{Acknowledgments}

This study was partially supported by grants from Wuhan University of Technology (40120596 and 3120621190).

\section{References}

[1] B. Jing, "Social learning and dynamic pricing of durable goods," Marketing Science, vol. 30, no. 5, pp. 851-865, 2011.

[2] Y. Chen, Q. Wang, and J. Xie, "Online social interactions: a natural experiment on word of mouth versus observational learning," Journal of Marketing Research, vol. 48, no. 2, pp. 238-254, 2011

[3] M. Yu, L. Debo, and R. Kapuscinski, "Strategic waiting for consumer-generated quality information: dynamic pricing of new experience goods," Management Science, vol. 62, no. 2, pp. 410-435, 2015.

[4] Y. Papanastasiou and N. Savva, "Dynamic pricing in the presence of social learning and strategic consumers," Management Science, vol. 63, no. 4, pp. 919-939, 2017.

[5] D. Crapis, B. Ifrach, C. Maglaras, and M. Scarsini, "Monopoly pricing in the presence of social learning," Management Science, vol. 63, no. 11, pp. 3586-3608, 2017.

[6] O. Carare, "The impact of bestseller rank on demand: evidence from the app market*," International Economic Review, vol. 53, no. 3, pp. 717-742, 2012.

[7] S. Sun, X. Zheng, and L. Sun, "Multi-period pricing in the presence of competition and social influence," International Journal of Production Economics, vol. 227, p. 107662, 2020.

[8] M. Hu, Z. Wang, and Y. Feng, "Information disclosure and pricing policies for sales of network goods," Operations Research, vol. 20, 2020.

[9] C. Pan, "Xiaomi says sales of its new 5G MI 10 phones have exceeded 1 million in mainland china," 2020.

[10] A. V. Banerjee, "A simple model of herd behavior," The Quarterly Journal of Economics, vol. 107, no. 3, pp. 797-817, 1992.

[11] S. Bikhchandani, D. Hirshleifer, and I. Welch, "A theory of fads, fashion, custom, and cultural change as informational cascades," Journal of Political Economy, vol. 100, no. 5, pp. 992-1026, 1992.

[12] T. Liu and P. Schiraldi, "New product launch: herd seeking or herd preventing?" Economic Theory, vol. 51, no. 3, pp. 627-648, 2012.

[13] J. Zhang, Y. Liu, and Y. Chen, "Social learning in networks of friends versus strangers," Marketing Science, vol. 34, no. 4, pp. 573-589, 2015.

[14] P. Feldman, Y. Papanastasiou, and E. Segev, "Social learning and the design of new experience goods," Management Science, vol. 65, no. 4, pp. 1502-1519, 2019.

[15] W. Peng, Z. Tian, and Y. Wang, "Price guarantee for advance selling in the presence of preorder-dependent social learning," International Journal of Production Economics, vol. 219, pp. 115-122, 2020.

[16] M. Hu, J. Milner, and J. Wu, "Liking and following and the newsvendor: operations and marketing policies under social influence," Management Science, vol. 62, no. 3, pp. 867-879, 2016. 
[17] B.-J. Jiang and B. Wang, "Impact of consumer reviews and ratings on sales, prices, and profits: theory and evidence," ICIS 2008 Proceedings, vol. 23, p. 141, 2008.

[18] Y. Qian, "Counterfeiters: foes or friends? How counterfeits affect sales by product quality tier," Management Science, vol. 60, no. 10, pp. 2381-2400, 2014.

[19] A. Parakhonyak and N. Vikander, "Optimal sales schemes for network goods," Management Science, vol. 65, no. 2, pp. 819-841, 2019.

[20] M. Hu, M. Shi, and J. Wu, "Simultaneous vs. sequential groupbuying mechanisms," Management Science, vol. 59, no. 12, pp. 2805-2822, 2013.

[21] K. Xie, Z. Mao, and J. Wu, "Learning from peers: the effect of sales history disclosure on peer-to-peer short-term rental purchases," International Journal of Hospitality Management, vol. 76, pp. 173-183, 2019.

[22] L. Castro and M. A. Toro, "The evolution of culture: from primate social learning to human culture," Proceedings of the National Academy of Sciences, vol. 101, no. 27, pp. 1023510240, 2004.

[23] R. Zheng, B. Shou, and J. Yang, "Supply disruption management under consumer panic buying and social learning effects," Omega, vol. 23, p. 102238, 2020.

[24] K. Jerath, S. Netessine, and S. K. Veeraraghavan, "Revenue management with strategic customers: last-minute selling and opaque selling," Management Science, vol. 56, no. 3, pp. 430-448, 2010.

[25] Y. V. Joshi, D. J. Reibstein, and Z. J. Zhang, "Turf wars: product line strategies in competitive markets," Marketing Science, vol. 35, no. 1, pp. 128-141, 2016.

[26] T. Puu and L. Gardini, Hotelling Type Duopoly and Oligopoly, Springer, Berlin, Germany, 2002. 